\title{
MEIO AMBIENTE E EDUCAÇÃO: PERCEPÇÃO AMBIENTAL DE JOVENS ALUNOS ACERCA DA ÁGUA (IFMT)
}

\author{
Adelson da Costa Ribeiro' \\ Tadeu João Ribeiro Baptista²
}

\section{Resumo}

O debate sobre a Percepção Ambiental (PA) revela-se importante para a Educação Ambiental (EA) dentro do Instituto Federal de Educação, Ciência e Tecnologia de Mato Grosso (IFMT), em prol da formação dos jovens estudantes sobre as questôes socioambientais. O objetivo deste estudo é verificar a PA dos discentes ingressos no Ensino Médio Integrado de Edificaçóes e Meio Ambiente do Campus Cuiabá Octayde Jorge da Silva e do Campus Cuiabá Bela Vista, além de ser possível também: identificar a PA de grupos escolares diferenciados por cursos; e delinear alguns aspectos para estratégias mais assertivas aos procedimentos das ações de EA no IFMT. Metodologicamente a pesquisa é descritiva e apresenta natureza quanti-qualitativa, sendo os dados obtidos através de questionário aplicado aos participantes. Ao se analisar os dados, os resultados demonstram que na questão dos diferentes níveis de categorização em relação ao ambiente foi detectado que os alunos apresentam apenas o que poderia ser chamado de percepção ambiental e isto reflete na profundidade não adequada sobre o saber ambiental. A conclusão da pesquisa apresenta mudanças no estudo de percepção para a verificaçáo do Nível de Consciência Ambiental dos indivíduos, no intuito de auxiliar a EA a agir nos indivíduos da sociedade moderna.

Palavras-chave: Percepção Ambiental. Jovens. IFMT.

1 Mestre, professor DE do Instituto Federal de Ensino, Ciência e Tecnologia de Mato Grosso (IFMT). E-mail: adelson.ribeiro@cba.ifmt.edu.br

2 Doutor, professor adjunto da Universidade Federal de Goiás (UFG). E-mail: tadeujrbaptista@ yahoo.com.br 


\section{Introdução}

O debate deste tema de pesquisa revela-se importante para as áreas do conhecimento relativo ao meio ambiente, bem como para a Educação, em particular, a Educaçáo Ambiental (EA) e, principalmente, para a melhoria da organização e das estratégias e práticas pedagógicas no Instituto Federal de Educaçáo, Ciência e Tecnologia de Mato Grosso (IFMT), auxiliando no desenvolvimento do conhecimento dos jovens estudantes sobre as questôes socioambientais.

De acordo com Fernandes et al. (2003), a pesquisa da Percepçáo Ambiental (PA) é o ponto de partida para as soluçóes dos problemas ambientais em pauta na atualidade, pois através dela se verificam as inter-relaçóes das questôes sociais, educacionais, culturais, econômicas, bem como as trabalhistas. Os dados apreendidos em uma pesquisa da PA refletem não só a realidade individual, como também, aspectos coletivos da sociedade na sua relação com a natureza. Fornece ainda alicerce para as açóes de educação ambiental nas comunidades do estudo no ambiente formal e para as atividades não formais.

A água é o recurso natural do meio ambiente que pode ser considerado o mais importante, devido a sua imprescindibilidade para a vida no planeta. As metas para uso racional da água nas organizaçôes federais brasileiras estáo cada vez mais rígidas. Isto trouxe à tona reflexôes sobre a política ambiental no IFMT, na qual nota-se uma possível dificuldade no planejamento dos programas, provavelmente pelo desconhecimento do público a ser envolvido, além da falta de uma política ambiental interna da própria instituição.

Várias são as pesquisas relativas à percepção ambiental, como os trabalhos de Castoldi et al. (2009), Malafaia e Rodrigues (2009), os quais foram tomados como referência do presente estudo. Estas pesquisas sobre percepção do meio ambiente diferem do presente estudo em que tem foco especial para a água.

A hipótese é de que, havendo diferenças nestas percepçóes, elas podem revelar fragilidades no desenvolvimento do saber ambiental dos discentes, bem como, no processo de formaçáo da cultura ambiental realizado pela Educaçấo Ambiental, na instituição de ensino do presente estudo.

O estudo buscou resposta à temática: qual é a percepção que os alunos ingressantes nos cursos integrados do IFMT em 2016 têm a respeito da água? O que acarretou no objetivo desta pesquisa em verificar a percepção ambiental dos discentes ingressados no Ensino Médio Integrado de Edificaçóes e Meio 
Ambiente do Campus Cuiabá Octayde Jorge da Silva e do Campus Cuiabá Bela Vista, respectivamente. E ainda consideraram-se como outros objetivos interligados à questáo: (1) identificar a PA de grupos escolares diferenciados por cursos, com foco também sobre o recurso natural água; e (2) delinear os aspectos importantes para a configuração das estratégias mais assertivas aos procedimentos das açóes de EA no IFMT.

Metodologicamente, a pesquisa é descritiva, a qual é normalmente utilizada quando:

[...] o foco essencial destes estudos reside no desejo de conhecer a comunidade, seus traços característicos, suas gentes, seus problemas [...], seus professores, sua educação, sua preparação para o trabalho, seus valores, [...] etc. (TRIVIÑOS,1987, p. 10).

Esta pesquisa apresenta, ainda, natureza quanti-qualitativa. Os dados foram obtidos através de questionário aplicado aos alunos matriculados no ano letivo de 2016, nos cursos já mencionados. Segundo Gressler (1993 apud CASTOLDI, 2009), o questionário é um procedimento ágil, com menos controle sobre o indivíduo, permitindo tempo para reflexão sobre as respostas, e a organização e posterior análise dos resultados, gerando dados quantitativos, inclusive.

A especificidade da delimitação à modalidade do integrado vem do interesse da pesquisa por verificar a percepção ambiental de jovens alunos do ensino médio. Além do fato de não existirem trabalhos anteriores sobre a percepção dos alunos do ensino médio do IFMT, ou seja, faltam dados iniciais de percepção dos estudantes para uma análise, deste modo, impossibilita avaliar a evolução dos alunos na instituição, por exemplo, sobre os formandos.

A escolha deste curso de Edificaçôes justifica-se pelo fato de ser um curso que ocorrem processos, no ensino técnico-prático e ao longo de vida profissional, que fazem uso de água de modo profuso, a exemplo da preparação de concreto e argamassa, da lavagem de máquinas, equipamentos e ferramentas, ou ainda da molhação de acessos e vias internas de obras.

Aplicou-se a pesquisa também aos alunos do curso de Meio Ambiente, que foi criado mais recentemente no Campus Bela Vista, em Cuiabá, este curso não existe no Campus Cuiabá Octayde. A escolha dos alunos desse curso advém da hipótese de que os seus ingressantes possuem diferenças de 
conhecimentos e percepção que formam a cultura ambiental em relação aos alunos ingressantes do curso de Edificaçóes, possibilitando a comparação dos resultados entre os cursos.

Este estudo foi submetido e aprovado pelo Comitê de Ética em Pesquisa do IFMT (CEP/IFMT) com número CAAE: 61687516.3.0000.8055. Durante o processo de aprovação, a pedido da CEP/IFMT, foi retirada a informação sobre sexo (masculino ou feminino), dado comum em qualquer pesquisa social e que seria interessante para o presente estudo para traçar o perfil dos envolvidos.

Os critérios de inclusão dos alunos participantes da pesquisa foram: alunos menores de 18 anos, não repetentes, que apresentaram o Termo de Assentimento Livre e Esclarecido (TALE) assinado pelos seus representantes legais (pais ou tutores), tendo em anexo a cópia de documento comprobatório ou mostrando o documento, além de preencherem e assinarem o Termo de Consentimento Livre e Esclarecido (TCLE); alunos devidamente matriculados no primeiro ano do IFMT nos cursos já mencionados; também se torna critério de inclusão a presença voluntária do estudante, no local e data da aplicação do questionário.

Deste modo, os critérios de exclusão foram: os alunos que não atenderam a todos os critérios de inclusão acima relatados, ou seja, alunos de outros cursos, alunos não matriculados regularmente no primeiro ano, com 18 anos completos, alunos que não apresentaram o TALE e o TCLE devidamente assinados. Foi garantido o sigilo aos participantes, que náo terão seus nomes ou fotos divulgados sem prévia autorização, pois a pesquisa está em total consonância com os critérios bioéticos preconizados pela Resolução/CNS no 466/2012 a respeito de estudos envolvendo seres humanos.

O estudo de campo foi realizado após aprovação da CEP/IFMT, ocorrida em fevereiro/2017, e que coincidiu com o período de provas bimestrais, por isso, se efetivou em março/2017. Ressalta-se que no curso de Edificações oferecem-se 50 vagas para alunos divididos em duas turmas de 25 alunos, anualmente, e no curso de Meio Ambiente, 30 vagas, perfazendo um total de 80 alunos ingressantes nesses cursos, ou seja, o máximo de 80 participantes neste estudo. A análise dos dados do questionário foi feita a partir da análise de conteúdo proposta por Bardin (1979).

O presente capítulo se estrutura em duas seções. Na primeira seção se aborda a crise hidrica da modernidade. A busca do homem em dominar a 
natureza, acarretando os problemas ambientais globais da atualidade, na qual se destacam a crise da água e as suas consequências para a saúde humana. Assim, a EA é apontada como ferramenta para formação de cidadãos mais conscientes, principalmente dos mais jovens, discutindo-se ainda a influência das mídias na relação da juventude e o meio ambiente. Traz o significado da percepçáo e diferindo-o de termos similares à PA, como: representação ambiental, concepção ambiental e consciência ambiental.

$\mathrm{Na}$ segunda seção são apresentados os resultados sobre a percepção dos alunos de acordo com os dados coletados, que são organizados em tabelas, procedendo-se à discussão dos dados, comparando-os com os de outras pesquisas selecionadas com relação ao tema, como: Silva (2016), Peltz (2010), ampliando o debate com o cruzamento entre os vários aspectos postos na presente pesquisa. A sistematização da visão ambiental dos alunos entrevistados, que poderia ser: romântica, reducionista, utilitarista, abrangente e a socioambiental, conforme Reigota (1995) e Fontana et al. (2002 apud MALAFAIA; RODRIGUES, 2009).

$\mathrm{Na}$ conclusão buscou-se demonstrar a percepção ambiental dos alunos e as contribuiçóes que se apreenderam neste trabalho, com enfoque nas proposiçôes para a Educação Ambiental, principalmente, do IFMT, a fim de auxiliar a atingir suas metas dentro do contexto socioambiental. Foi sugerida, por fim, uma nova utilização prática da PA para a verificação do Nível de Consciência Ambiental.

\section{A crise hídrica da modernidade, educação ambiental e a percepção ambiental da juventude}

A busca do homem pela manipulação eficiente sobre a natureza e a exploração dos recursos naturais ambientais teve seu esplendor no advento da Revolução Industrial no século XVIII, somada ao exponencial desenvolvimento da ciência e tecnologia na época, tendo como referência ou justificativa o progresso do gênero humano, conceito este bastante contraditório apontado por Tassara (2006).

Para ela, o equívoco na visão positivista sobre o termo progresso é ser contínuo e ilimitado, conceito bastante combatido também pela escola de Frankfurt no século XX. Segundo a autora, o progresso: 
[...] vinha se referindo, em seu sentido radical e quando não acompanhado de especificação adjetiva, à história universal do gênero humano e indicava um processo presumido de avanço contínuo e unilinear, no qual as aquisiçóes se acumulariam concorrendo para um aperfeiçoamento das condiçóes materiais e morais do gênero humano, supostamente ilimitado. (TASSARA, 2006, p. 225).

Diante da industrialização europeia, a degradação ambiental se torna uma consequência aceitável em vista do progresso atingido, o que também legitimou o desejo de melhorias de condiçôes materiais e sociais da burguesia. Entretanto, nas décadas de 1970 a 1990, se observa uma conscientizaçáo sustentável em prol do meio ambiente de alguns setores da sociedade na contramão dos preceitos neoliberalistas.

Um dos marcos dos caminhos que levam ao desenvolvimento sustentável é o Relatório Brundtland, trabalho proposto pela Organização das Naçóes Unidas (ONU) com o conceito de desenvolvimento sustentável. Mas o conceito de desenvolvimento sustentável e humano defendido pela $\mathrm{ONU}$ não supõe mudanças nas relações vigentes e inseridas pelo capitalismo, pontuando como se os recursos naturais fossem ilimitados e sua exploração sustentável não afetasse o meio ambiente.

Por isso, Loureiro (2004, p. 16) aponta que “[...] dialeticamente falando, para construirmos um novo patamar societário e de existência integrada [...], precisamos superar as formas de alienação que propiciam a dicotomia sociedade/natureza”.

Perante o desenvolvimento tecnológico e da ciência da atualidade, o ser humano deveria ser capaz de encontrar soluçóes, resolver os problemas e equacionar a crise ambiental do mundo contemporâneo. A mesma ciência tecnológica e também a social que se engajaram, no desenvolvimento do modelo de produção proposto, não conseguem dar soluçóes substanciais às questôes ambientais, deste modo, a crise ambiental "[...] é, portanto, uma crise política da razáo” (TASSARA, 2006, p. 227, grifo nosso).

Para Leff (2011, p. 309), a crise ambiental é compartilhada por uma crise de civilização, "[...] que se manifesta pelo fracionamento do conhecimento e pela degradação do ambiente, [...] guiado[s] pela racionalidade tecnológica e pelo mercado livre". O fracionamento do conhecimento, principalmente 
o das ciências da natureza, dificulta os estudos voltados ao meio ambiente e sua complexidade, que seriam importantes para se desenvolverem soluçóes às questóes ambientais mais pertinentes.

A negação da complexidade ambiental traz como consequência a crise do saber ambiental, a qual surge "[...] como todo um campo do real negado e do saber desconhecido pela modernidade" (LEFF, 2011, p. 309). As crises trazidas pela modernidade são embasadas no pragmatismo do modelo econômico vigente no mundo.

Destaca-se das crises ambientais da atualidade a crise hídrica. A questão do estresse hídrico pela demanda de consumo acarreta o declínio da disponibilidade do recurso natural água em várias regióes do mundo. Observa-se que o fenômeno escassez também tem ligação com o crescimento populacional (principalmente com a urbanização) e com o aumento do consumo das mercadorias produzidas.

Ainda segundo Tundisi (2008), a escassez é advinda de mudanças climáticas que provocam eventos hidrológicos extremos como chuvas intensas favorecem períodos longos de seca, o que aumenta, por conseguinte, afetam mais as populaçôes carentes.

Outras consequências desse "[...] conjunto de problemas [...], e, em respostas a essas causas, há interferências na saúde humana e saúde pública” (TUNDISI, 2008, p. 8, grifo nosso). Isto afeta de modo significativo a qualidade de vida dos indivíduos e influencia o desenvolvimento econômico e social da sociedade a que eles pertencem. Mesmo com os avanços científicos e tecnológicos, a demanda de água torna-se fator limitante e crescente ao modo de exploração que a sociedade moderna preconiza.

A EA se apresenta como possibilidade de transformaçóes culturais com o intuito de formação de uma consciência ambiental nos indivíduos, afastando-os do enfoque ecológico. Para tanto, é necessário a troca de conhecimento entre os profissionais educadores das disciplinas científicas nas relações multidisciplinares ${ }^{3}$ ou interdisciplinaridade.

A transversalidade consta nas diretrizes da Política Nacional de Educação Ambiental (ProNEA) juntamente com a interdisciplinaridade. No entanto, esta última, para Leff (2011), deve ser superada pela transdisciplinaridade. A transdisciplinaridade ocorre quando há a desconstrução disciplinar, na buscar

3 Multidisciplinaridade é a “[...] colaboração de profissionais com diferentes formações disciplinares" (LEFF, 2011, p. 312). 
da reconstrução de uma nova racionalidade ambiental através da inter-relação do conhecimento científico com o "não científico", ou seja, também da realidade dos sujeitos envolvidos.

Neste sentido, a EA torna-se ferramenta plausível para a construção e reconstrução do novo saber ambiental e também social, para formação de cidadãos com consciência socioambiental, junto aos espaços formais de educação hibridados com os não formais, para ir contra a cultura estabelecida como dominante que expropria a natureza e o próprio homem, mesmo diante do uso intenso das mídias.

As conquistas tecnológicas efetivamente alteraram a forma de comunicação entre as pessoas, isto é histórico para os jovens modernos. A mídia tradicional, ou de massa, quando aborda algumas temáticas a respeito dos jovens, traz normalmente informaçóes de cunho cultural e de comportamento, dentro do padrão estabelecido, evidentemente.

A intensidade dessa atuação das mídias sobre os jovens pode ser entendida no uso do aparato tecnológico para divulgaçáo, quase que simultânea, dos problemas dos jovens que ainda não estão integrados à ordem estabelecida. Atuação que se denomina socialização, integralização ou racionalização dos indivíduos.

Percebe-se ainda que este processo, mesmo que seja sem armas, tende a ser violento, uma vez que o indivíduo náo deve aceitar passivamente o controle de seus instintos naturais, uma vez que, "[...] as renúncias que disto resultam não ocorrem sem atritos” (HORKHEIMER; ADORNO, 1973, p. 133).

Paulatinamente, os indivíduos divergentes têm seus instintos naturais dominados para ajustar-se aos padróes e normas aceitáveis, à medida que vão se distanciando de seus ideais políticos, transformando e "[...] desenvolvendo atitudes e opiniôes políticas adequadas às necessidades da sua nova situação" (IANNI, 1968, p. 140). Ocorre a "perda" das convicçôes do indivíduo adquiridas anteriormente, tornando meramente transitórias tais convicçóes, num processo bastante repressivo, mas que para os indivíduos alienados é a normalidade da situação real.

A atuação na completa transformação do indivíduo continua posteriormente em vários momentos de sua vida, realizando a manutenção da personalidade do indivíduo dentro dos padróes exigidos pela sociedade atual, autuando também no seio familiar, pois os "[...] primeiros sintomas da própria alienação, que se manifesta no próprio lar” (IANNI, 1968, p. 230). 
A interferência da mídia também chega à instância escolar. A mídia de massa que pretende ser parceira na interdependência entre as instâncias tradicionais e destas com ela mesma, pois se percebe que "[...] para o bem ou para o mal, [...] [a mídia] está presente em nossas vidas, transmitindo valores e padróes de conduta, socializando muitas geraçôes" (SETTON, 2002, p. 109).

Por meio da percepção ambiental seria possível verificar, por exemplo, se a interferência da tecnologia entre os jovens é de todo ruim ou não, pois, todavia, as mídias podem vir a auxiliar na divulgação de ideias ambientalistas conectando todas as juventudes. Por esta razão é necessária a melhor compreensão sobre a percepção ambiental.

Merleau-Ponty (2011) ilustra a importância da percepção empírica ou segunda, na percepçáo do objeto pelo sujeito, do qual se pode abstrair ainda que a percepção não seja uma operação intelectual ou do pensamento tão somente, como se pensava na visáo do sujeito cindido, mas uma interaçáo através dos sentidos do corpo. Para o autor, a percepção é uma atividade do corpo, o que é contrário aos preceitos clássicos empiristas e positivistas do corpo e mente cindidos.

A experiência perceptiva é uma experiência do corpo, pois, antes de haver reflexôes mentais para ocorrer objetivação, o mundo é reconhecido por meios subjetivos do corpo, na corporeidade. Deste modo, no interior do sujeito, a percepção indica desde o fato de seu nascimento:

\section{[...] a contribuiçáo perpétua de sua corporeidade, uma co-} municaçáo com o mundo mais velha que o pensamento. Eis por que eles obstruem a consciência e são opacos para a reflexão. (MERLEAU-PONTY, 2011, p. 342, grifo nosso).

Mas o que difere a percepção da representação? Na psicologia social, interessante é apresentar, neste estudo de representaçóes, a questão da importância da representação social para a coletividade, em que o entendimento da representação social é o adotado neste estudo:

[...] em outras palavras, a representação iguala toda imagem a uma ideia e toda ideia a uma imagem [...]. Do mesmo modo, nossas coletividades hoje não poderiam funcionar se não se criassem representaçóes sociais baseadas no tronco das teorias e 
ideologias que elas transformam em realidades compartilhadas, relacionadas com as interaçóes entre pessoas que, então, passam a constituir uma categoria de fenômenos à parte. (MOSCOVICI, 2007, p. 46-48).

Divergindo frontalmente ao que se compreende de percepção como atividade corporal, a concepção, ou o ato de.

[...] "conceber" é uma operação da mente, um modo de pensar específico do qual se está ou se pode estar consciente. Porque é uma operação da mente, "concepção" é uma ação, e essa só pode provir de algo que é "vivo" e "ativo". "Concepçâa” supóe um "poder no ente que [a] opera" sobre. (REID, 2002, p. 20-22 apud PICH, 2010, p. 145, grifo do autor).

A necessidade de estudar a consciência ocorre devido ao fato de que, na história da filosofia, a busca incansável pela verdade como foco primordial passa pelo estudo da formação da consciência humana, a qual jamais teve conclusão.

Essa vem a ser a crítica à filosofia kantiana por parte de Hegel (2003, p. 135), o qual menciona que "[...] nos modos precedentes da certeza, o verdadeiro é para a consciência algo outro que ela mesma”. O autor assim evidencia que a verdade ou o verdadeiro é a própria consciência ou espírito de uma determinada época (histórica), já que a verdade ou realidade, que não era mais absoluta e sim dinâmica, dava-se de uma forma dialética.

A consciência é o que dá significado às coisas do mundo, sendo a consciência o próprio espírito - mundo sensível, e este é o foco da ideologia helgeliana da qual Marx e Engels (1998) de forma crítica invertem a posição da questão idealista. Marx e Engels (2007) dão ênfase à materialização da sua construção ao invés das discussões no mundo sensível das ideias, vislumbrando a necessidade de reestruturação das categorias do idealismo hegeliano para uma que trate da materialidade e realidade concreta do homem e das suas relaçóes.

Considera-se que as relaçóes sociais são precárias no começo e, após o desenvolvimento (histórico) da consciência, o homem percebe que vive em sociedade, logo, evidencia que mesmo antes a consciência já é um produto social: 
[...] a mera consciência do meio sensível mais imediato e consciência do vínculo limitado com outras pessoas e coisas exteriores ao indivíduo que se torna consciente. (MARX; ENGELS, 2007, p. 35, grifo dos autores).

Os termos do estudo devem aparecer no decorrer do trabalho, analisando-se o seu emprego mais adequado aos resultados da pesquisa de modo hierárquico. Por exemplo, quando o jovem inquirido demonstre ter uma vivência ou juízo sobre o assunto, demonstrando a reflexão realizada, o termo seria concepção. Para uma situação em que apenas for demonstrada uma imagem ou ideia da questão além de sensaçôes relativas ao objeto, o termo correto seria representação.

Ainda no caso de as respostas observadas denotarem apreensão através de uma atividade ou experiência do corpo ocorrida através da corporeidade, o termo seria percepção. Todos os termos devem ter guardada a relação com a consciência, a qual tem na ideia de formação da consciência ambiental dos indivíduos, não como aspecto final de elucidação dos mistérios da consciência como aponta Damásio (2000), mas ao ponto que se aproxime dos objetivos mais importantes para a Educaçáo Ambiental. A seguir apresentam-se os resultados da pesquisa.

\section{A percepção ambiental de jovens alunos do IFMT}

Conforme os requisitos apontados na introdução, para a coleta de dados em campo, pretende-se demonstrar os resultados obtidos na pesquisa com o uso de questionário que contém um total de 12 perguntas abertas e algumas fechadas. São apresentados em tabelas e discutidos alguns dados das questóes propostas na pesquisa, a seguir.

Com as respostas do questionário se teve o objetivo de verificar a Percepção Ambiental dos participantes, alunos do IFMT dos cursos de Edificaçóes, turmas A e B, e de Meio Ambiente. No entanto, como as turmas A e B são de um único curso e do mesmo campus, foi unificada a quantidade de participantes dessas turmas, já que a análise foi feita entre os cursos de Edificaçôes (EDI) e Meio Ambiente (MA) e não entre turmas. E quando somadas as turmas de edificaçóes chega-se ao número de 15 alunos participantes, conforme se apresenta na tabela a seguir: 
Tabela 1 - Quantidade de alunos participantes da pesquisa por curso

\begin{tabular}{l|c}
\hline CURSOS & Frequência $^{4}$ \\
\hline Edificações (EDI) - Turma A e Turma B & 15 \\
\hline Meio Ambiente (MA) & 7 \\
\hline TOTAL & 22 \\
\hline
\end{tabular}

Fonte: Elaborado pelo autor.

Observa-se na tabela acima que apenas 22 alunos (27,50\%) compareceram no dia da aplicação do questionário e estavam em total conformidade com as exigências da pesquisa. No entanto, mesmo após várias tentativas, para que mais alunos participassem, a quantidade dos que atendiam os pré-requisitos não se alterava.

Pode-se atribuir esse fato à falta de interesse em participar da pesquisa ou sobre o tema meio ambiente, embora se tenha feito a apresentação citando a relevância do presente estudo. Mesmo assim, não se obteve êxito em agregar mais discentes, o que no geral pode ser indicador de fragilidade da EA na instituição.

Destaca-se que a idade dos participantes voluntários variou entre 14 e 16 anos, em que a idade média dos estudantes é de 15,38 anos, com desvio-padrão de 0,59 ano. Para o estudo, a faixa etária é aspecto importante na compreensão do estágio da formação humana e profissional dos jovens alunos.

Não se pôde verificar a distribuição de sexo entre os entrevistados, pois, atendendo à solicitaçáo da CEP/IFMT, se excluiu o item do instrumento de pesquisa. Em outra pesquisa realizada em uma escola pública da região metropolitana de Porto Alegre (RS), com estudantes do Ensino Médio, contatou-se que: "A maioria constitui-se de meninas (55\%)" (PELTZ et al., 2010, p. 90). Não foi possível realizar comparaçôes com estas pesquisas relacionadas, pela ausência do dado e, ainda se destaca que a CEP/IFMT, em seu parecer, confunde sexo com gênero em uma pesquisa no âmbito educacional.

Alguns dados serão apresentados de forma descritiva, a fim de demonstrar o máximo de dados coletados dos jovens discentes. Considerando-se os Critérios de Classificação Econômica Brasil (CCEB), vigente no ano de 2016, o valor do salário mínimo vigente de $\mathrm{R} \$ 937,00$ e a concentraçáo de renda familiar indicada pelos jovens participantes entre 1 e 4 salários míni-

4 O termo "Frequência" na tabela 1 , ou "Freq." nas tabelas seguintes, diz respeito à quantidade de alunos que responderam a cada pergunta do questionário. 
mos, destaca-se que a maioria dos alunos, $63,64 \%$, está entre os estratos C2 a B2. Apreende-se deste cenário que a renda familiar da maioria dos alunos entrevistados não é elevada.

Pode-se verificar ainda que, em mais da metade das respostas, ambos os pais possuem curso superior, cerca de 54,50\%. E quando inclusos os casos em que somente as mães dos alunos possuem formação superior, aumenta o percentual para $60 \%$ das indicaçóes. As informaçóes revelam que os alunos entrevistados possuem uma condição familiar com nível educacional significativo, o que pode influenciar na sua formação humana.

A inclusão do homem na natureza para os jovens alunos, quando questionados sobre sua visão sobre a natureza, os discentes apresentaram respostas em que houve divisão igual para a inclusão e exclusão do homem na natureza, com $50 \%$ de indicaçóes para cada situação. Esta situação difere das pesquisas de referência como a de Castoldi et al. (2009, p. 69), que afirmam: "Quanto à inclusão do homem no meio ambiente 37\% dos alunos o incluíram, e 63\% não o incluíram".

De acordo com Reigota (1995) e Fontana et al. (2002 apud MALAFAIA; RODRIGUES, 2009), na classificação sobre o meio ambiente se tem: romântica - visão da "mãe natureza", em que o homem não está inserido; utilitarista - fonte de recursos para o homem, antropocêntrica; abrangente natureza ampla e complexa, inclui aspectos naturais e de atividades humanas; reducionista - refere-se estritamente aos aspectos físicos naturais, como a água, o ar, sem enaltecer a natureza, e exclui o ser humano; socioambiental - tem abordagem histórico-cultural, em que há interferência do homem, apropriando-se dos elementos da natureza, tendo-o como principal degradador da natureza no contexto histórico.

Portanto, pode-se deduzir dos dados e do contexto da presente pesquisa que os alunos que excluem o homem da natureza foram classificados na categoria reducionista, e possuem uma representaçâo ambiental atrelada aos conceitos ecológicos constantes nos conteúdos didáticos tradicionais. Infere-se ainda que os alunos que incluem o homem na natureza se aproximam da categoria abrangente, pois conseguem conceber em patamares significativos de saberes ambientais, mas, evidentemente, que ainda em uma concepção ambiental prematura.

A respeito das fontes de informações sobre o meio ambiente, a grande maioria dos alunos entrevistados indicou que busca informaçóes nas mídias, 
com $64 \%$ do total de entrevistados, e apenas 36\% dos discentes entendem que a fonte de informação sobre o meio ambiente está na escola, instância tradicional da educação formal. As respostas mídias para a questão contrapóem-se às respostas dos alunos que incluem o homem no meio ambiente e têm visão abrangente.

As razóes para isto não ficam claras neste momento da pesquisa, mas esta contradição dos sujeitos revela a falta de clareza sobre os conceitos ambientais que eles têm, o que os remete a uma percepção ainda primária. Os dados demonstram o potencial de influência da indústria cultural sobre os jovens.

Os principais problemas ambientais na opinião dos jovens, os quais indicaram temas bastante atuais e disseminados pelas mídias locais, tendo destaque para poluição (ar e solo) e para o desmatamento, obtendo 23,08\% e 21,15\% das respostas, respectivamente. Observa-se praticamente uma conformidade entre respostas dos alunos de Edificaçóes e de Meio Ambiente. Os problemas apontados têm enfoque reducionista, bem característico da influência dos meios de comunicação de massa. Além de serem mencionados temas ligados à problemática da água, como escassez e poluição dela.

$\mathrm{Na}$ responsabilidade de cuidar da água, as respostas recaíram para todos individualmente. Os dados refletem que uma maioria de $64 \%$ dos discentes detêm aspectos da visão abrangente sobre o tema água (apesar de se tratar de um aspecto físico e segregado do meio ambiente, é o foco estrategicamente delimitado na pesquisa). Ficou denotado que a visão para o meio ambiente de modo geral, igualmente dividido entre a visão reducionista e abrangente, difere do caso da tabela 2 a seguir, sobre a água, de maioria abrangente.

Comparando-se com a questão acerca das fontes de informaçóes dos alunos sobre o meio ambiente, ficaram evidenciadas naqueles dados a correlação e a influência das mídias na obtenção de informação sobre o meio ambiente e na formação dos jovens alunos. Na presente tabela 2, se deduz que é notório que as mídias também sejam a fonte de informaçóes sobre o tema água para os entrevistados, assim como é para o meio ambiente. 
Tabela 2 - A responsabilidade de cuidar da água para os discentes*

\begin{tabular}{l|c|c|c}
\hline \multirow{2}{*}{ Responsáveis } & \multicolumn{2}{|c|}{ CURSOS } & \multirow{2}{*}{ Total } \\
\cline { 2 - 4 } & EDI & MA & \\
\cline { 2 - 4 } & Freq. & Freq. & Freq. \\
\hline Governos & 3 & 0 & 3 \\
\hline Sociedade & 4 & 2 & 6 \\
\hline Todos Individualmente & 11 & 5 & 16 \\
\hline TOTAL & 18 & 7 & 25 \\
\hline
\end{tabular}

Fonte: Elaborado pelo autor.

* Poderia haver mais de uma resposta a esta pergunta.

No entanto, esta forte influência ainda não afetou, ao menos, a maioria dos discentes desta pesquisa, para ter uma visão mais reducionista sobre a água. Mas é plausível entender que a influência da mídia ainda não tenha afetado estes jovens discentes, pelo fato de eles ainda não serem consumidores-alvo de produtos ligados ao tema água. Pois, conforme os dados da pesquisa indicam, os alunos ainda residem com familiares, pais ou responsáveis, não tendo ainda o poder de decisão de consumo.

Os dados revelam que, por não haver ação conclusiva da socialização midiática sobre estes alunos na questão, abre-se a possibilidade de atuação da EA mesmo no uso da mídia internet, mas em prol da preservação da água e do meio ambiente. No intuito de contrapor a indústria cultural, pois ela "priva seus consumidores do que continuamente lhes promete. [...] A indústria cultural não sublima, mas reprime e sufoca" (ADORNO; HORKHEIMER, 2009, p. 21).

$\mathrm{Na}$ tabela 3, a seguir, observa-se que praticamente não há diferença entre respostas dos alunos de Edificaçóes e de Meio Ambiente, sendo bastante congruentes, em que $95,45 \%$ dos participantes da pesquisa náo participam de atividades ou movimentos que tenham o intuito de proteger a água. 
Tabela 3 - Participação dos alunos em movimentos de proteção à água

\begin{tabular}{l|c|c|c}
\hline \multirow{2}{*}{ Respostas } & \multicolumn{2}{|c|}{ CURSOS } & \multirow{2}{*}{ Total } \\
\cline { 2 - 4 } & EDI & MA & Freq. \\
\cline { 2 - 4 } & Freq. & Freq. & 1 \\
\hline Sim & 1 & 0 & 21 \\
\hline Não & 14 & 7 & 22 \\
\hline TOTAL & 15 & 7 & \\
\hline
\end{tabular}

Fonte: Elaborado pelo autor.

Esta situação e outras mencionadas no decorrer do estudo indicam a fragilidade da EA na instituição, principalmente no desenvolvimento de atividades com os discentes, o que fica evidenciado na resposta abaixo:

Já participei num projeto do ano retrasado, em minha antiga escola, onde fizemos um esquema para que pudéssemos reutilizar a água que escorre do ar-condicionado, economizando litros d'água. (EEDIA5, grifo nosso).

A seguir se colocam as consideraçóes finais.

\section{Considerações finais}

Ao se analisar os dados, os resultados demonstram que não existe uma diferença entre a percepção ambiental dos alunos dos cursos avaliados. Além disso, ao se verificar de maneira mais específica a questão dos diferentes níveis de categorização em relação ao ambiente, foi detectado que os alunos apresentam apenas o que poderia ser chamado de percepçáo ambiental, porque isto reflete em nível de profundidade não adequado sobre o saber ambiental.

Diante dos aspectos observados na pesquisa, foi possível verificar as fragilidades na estrutura da Educação Ambiental na instituição, possibilitando a sugestáo de algumas propostas preliminares. Ao se olhar para os dados e o confronto deles com a literatura, é possível identificar possíveis pistas que levam a inferir uma provável necessidade de uma reorganização pedagógica da EA na instituição.

A principal contribuição que o estudo apresenta é a real necessidade de se realizar uma releitura na classificação ambiental da visão dos indivíduos, 
com mudanças no estudo de percepção para a verificação do Nível de Consciência Ambiental deles.

\section{REFERÊNCIAS}

CASTOLDI, Rafael et al. Percepção dos Problemas Ambientais por Alunos do Ensino Médio. Revista Brasileira de Ciência, Tecnologia e Sociedade, São Carlos, UFSCAR, v. 1, n.1, p. 56-80, 2009.

FERNANDES, Roosevelt $S$. et al. Uso da Percepçáo Ambiental como Instrumento de Gestáo em Aplicaçóes Ligadas às Áreas Educacional, Social e Ambiental, 2003.

HEGEL, Georg Wilhelm Friedrich. Fenomenologia do espírito. Tradução de Paulo Menezes com colaboração de Karl-Heing Efken e Jorge Nogueira Machado. 7. ed. rev. Petrópolis: Vozes, 2003.

HORKHEIMER, Max; ADORNO, Theodor Wiesengrund (Orgs.). Temas básicos da sociologia. São Paulo: Cultrix, 1973.

. O iluminismo como mistificação das massas. In: ADORNO, Theodor

Wiesengrund; HORKHEIMER, Max. Indústria Cultural e Sociedade. Seleção de textos Jorge Mattos Brito de Almeida, traduzido por Juba Elisabeth Levy. São Paulo: Paz e Terra, 2009. p. 5-44.

IANNI, Octávio. O jovem radical. In: BRITO, Sulamita de. (Org.). Sociologia da juventude: da Europa de Marx à América Latina de hoje. Rio de Janeiro: Zahar, 1968. v. 1.

LEFF, Henrique. Complexidade, interdisciplinaridade e saber ambiental. Revista Olhar do professor, Ponta Grossa, UEPG, 2011.

LOUREIRO, Carlos Frederico Bernardo. Educar, participar e transformar em educaçẫo ambiental. Revista brasileira de educaçáo ambiental, Brasília, Rede Brasileira de Educação Ambiental, n. 0, p. 13-20, nov. 2004.

MALAFAIA, Guilherme; RODRIGUES, Aline Sueli de Lima. Percepção ambiental de jovens e adultos de uma escola municipal de ensino fundamental. Revista Brasileira de Biociências, Porto Alegre, UFRGS, v. 7, n. 3, p. 266-274, jul./set. 2009.

MARX, Karl; ENGELS, Friedrich. A ideologia alemã. Tradução Luis Claudio de Castro e Costa. São Paulo: Martins Fontes, 1998.

MERLEAU-PONTY, Maurice. Fenomenologia da percepçáo. Tradução Carlos Alberto Ribeiro de Moura. 2. ed. São Paulo: Martins Fontes, 2011.

MOSCOVICI, Serge. Representaçóes sociais: investigaçóes em psicologia social. Tradução Pedrinho A. Guareschi. 5. ed. Petrópolis: Vozes, 2007. 
PELTZ, Lidiane, el al. Resiliência em estudantes do Ensino Médio. Revista Semestral da Associaçáo Brasileira de Psicologia Escolar e Educacional, São Paulo. v. 3, n. 1, p. 8794, jan./jun. 2010.

PICH, Roberto Hofmeister. Thomas Reid sobre concepção, percepção e relação mente-mundo exterior. Revista Eletrônica Veritas, Porto Alegre, Pucrs, v. 55, n. 2, p. 144-175, maio/ago. 2010.

REIGOTA, Marcos. Meio ambiente e representaçáo social. Série: Questôes da nossa época, 41. São Paulo: Cortez, 1995.

SETTON, Maria da Graça Jacintho. Família, escola e mídia: um campo com novas configuraçôes. Educaçáo e Pesquisa, São Paulo, v. 28, n. 1, p. 107-116, jan./jun. 2002.

TASSARA, Edna Terezinha de Oliveira. O pensamento contemporâneo e o enfrentamento da crise ambiental: uma análise desde a psicologia social. In: CARVALHO, Isabel Cristina Moura de et al. (Org.). Pensar o Ambiente: bases filosóficas para a Educação Ambiental. Posfácio. p. 221-233. Brasília: Ministério da Educação, Secretaria de Educação Continuada, Alfabetização e Diversidade, UNESCO, 2006.

TRIVIÑOS, Augusto N. S. Introduçáa à pesquisa em Ciências Sociais: a pesquisa qualitativa em educação. São Paulo: Atlas, 1987.

TUNDISI, José Galizia. Recursos hídricos no futuro: problemas e soluçôes. Estudos Avançados, São Carlos, IIE, v. 22, n. 63, p. 1-16, 2008. 